\title{
Comerciacoop, la cooperativa de los boyacenses (1996-2016). Un estudio de caso en la historia empresarial del sector cooperativo colombiano
}

\author{
Carlos Alberto Molina Rodríguez \\ Universidad Pedagógica y Tecnológica de Colombia - UPTC \\ camolina0411@hotmail.com \\ Ingrith Marcela Cano Cancelado \\ Universidad Pedagógica y Tecnológica de Colombia - UPTC \\ zuechia@hotmail.com \\ Melissa Pedroza Buitrago \\ Universidad Pedagógica y Tecnológica de Colombia - UPTC \\ mpedroza1@hotmail.com
}

DOI: https://doi.org/10.21158/01208160.n82.2017.1655

Fecha de recepción: 6 de marzo de 2017

Fecha de aprobación: 3 de abril de 2017

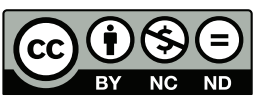

Cómo citar este artículo/ To reference this article/ Comment citer cet article/ Para citar este artigo:

Molina, C. A.; Cano, I. M. y Pedroza, M. (2017). Comerciacoop, la cooperativa de los boyacenses (1996-2016). Un estudio de caso en la historia empresarial del sector cooperativo colombiano.

Revista EAN, 82, pp. 199-218. https://doi.org/10.21158/01208160.n82.2017.1655

\section{Resumen}

El presente artículo se propone como objetivo principal dar cuenta de los resultados de la investigación que tuvo como fin realizar la historia empresarial de la Cooperativa de Comerciantes Comerciacoop. En dicho proyecto, se establecieron además como objetivos específicos: la periodización de los acontecimientos que han influido en el crecimiento económico y en el desarrollo empresarial de la Cooperativa; la determinación del papel cumplido por el gestor y director de los procesos administrativos de la Cooperativa; y el análisis de los procesos administrativos llevados a cabo en la Cooperativa, que han permitido la evolución en sus condiciones sociales y organizacionales. Este proceso investigativo se estructuró en tres etapas específicas: la recolección de información, la sistematización y análisis y la escritura de documentos y utilizó como base metodológica la historia empresarial.

\section{Palabras clave}

Historia empresarial, cooperativa de ahorro y crédito, Comerciacoop, empresariado, estudio de caso.

\footnotetext{
1 Doctor en Ciencias de la Educación. Magíster en Lingüística Española del Instituto Caro y Cuervo. Licenciado en Filología e Idiomas por la Universidad Libre. ORCID: http://orcid.org/0000-0002-0403-8589

2 Administradora de Empresas por la Universidad Pedagógica y Tecnológica de Colombia.

3 Administradora de Empresas por la Universidad Pedagógica y Tecnológica de Colombia.
} 


\title{
Comerciacoop, a Cooperative in Boyaca (1996-2016). A Case Study of Managerial History from the Colombian Cooperative Sector
}

\begin{abstract}
This article aims at showing research outcomes regarding company history of the Traders Cooperative named Comerciacoop. In this project, specific objectives have been clearly established: the periodization of different events resulting from economic growth and company development of this cooperative, the description of the role played by the manager in the administrative processes carried out in such cooperative, which have contributed to the evolution of social and organizational conditions. This research study has been made in three stages: collecting information; systematizing and analyzing information; and writing documents, using company history as its basic methodology.
\end{abstract}

Key words. Company history, credit and saving cooperative, Comerciacoop, management, case study.

\section{Comerciacoop, la coopérative des habitants de Boyaca (1996-2016). Une étude de cas de I'histoire entrepreneuriale du secteur coopératif colombien}

Resumé. Cet article a pour objectif principal de rendre compte des résultats de la recherche ayant pour but la réalisation de l'histoire entrepreneuriale de la Coopérative commerçante Comerciacoop. Les objectifs spécifiques de ce projet sont : I'historique des événements ayant contribué à la croissance économique et au développement entrepreneurial de la Coopérative; la détermination du rôle accompli par le dirigeant et directeur des processus administratifs de la Coopérative; l'analyse des processus administratifs réalisés dans la Coopérative ayant permis l'évolution des conditions sociales et organisationnelles. Ce processus investigatif a été divisé en trois étapes spécifiques : le recueil d'informations, la systématisation, l'analyse de l'écriture de documents et l'utilisation de l'histoire entrepreneuriale comme base méthodologique.

Mots clefs. Histoire entrepreneuriale, coopérative d'épargne et de crédit, Comerciacoop, entreprenariat, étude de cas.

\section{Comerciacoop, a cooperativa dos boyacenses (1996-2016). Um estudo de caso na história empresarial do setor cooperativo colombiano}

\begin{abstract}
Resumo. O presente artigo tem como objetivo principal dar conta dos resultados da pesquisa que teve como fim realizar a história empresarial da Cooperativa de Comerciantes Comerciacoop. Neste projeto, estabeleceram-se como objetivos específicos: a periodização dos acontecimentos que influenciaram o crescimento econômico e o desenvolvimento empresarial da Cooperativa; a determinação do papel realizado pelo gestor e diretor dos processos administrativos da Cooperativa; e a análise dos processos administrativos realizados na Cooperativa, que têm permitido a evolução em suas condições sociais e organizacionais. Este processo investigativo estruturou-se em três etapas específicas: a coleta de informação, a sistematização e análise, e a escrita de documentos. Utilizou-se como base metodológica a história empresarial.
\end{abstract}

Palabras chave. História empresarial, cooperativa de poupança e crédito, Comerciacoop, empresariado, estudo de caso. 


\section{Introducción}

a historia empresarial es un tipo de investigación válido en la formación de administradores de empresas, más aún cuando, desde una facultad o escuela de administración de empresas, se pretenda construir una historia regional, con el fin de lograr una mejor interacción con su entorno. Asimismo, se han de reconocer las cooperativas como un tipo particular de empresa: pertenecen al sector solidario de la economía, son de propiedad conjunta, se controlan de manera democrática y obedecen a la asociación autónoma de personas unidas voluntariamente, con el fin de satisfacer sus necesidades y aspiraciones económicas, sociales y culturales comunes. Así, en cuanto empresa, la cooperativa puede ser objeto de estudio de la historia empresarial.

Antes de abordar la perspectiva histórica, se puede mencionar el papel que desempeña el sector solidario en el desarrollo económico y social de un país, pues incide de manera positiva en la generación de empleo y en la mejora de la calidad de vida de gran parte de la población, especialmente a través de ahorro, crédito, educación, salud, transporte, servicios, y múltiples beneficios proporcionados por medio de cooperativas. Una cooperativa otorga a sus miembros beneficios más allá de lo económico: cumple una función social e individual, cada tipo de cooperativa es de vital importancia para el bienestar de la población y, a partir de ellas, se pueden alcanzar objetivos de una manera segura y confiable.

De acuerdo con la legislación colombiana, la economía solidaria es un sistema socioeconómico, cultural y ambiental conformado por el conjunto de fuerzas sociales organizadas en formas asociativas identificadas por prácticas autogestionarias solidarias, democráticas y humanistas, sin ánimo de lucro para el desarrollo integral del ser humano como sujeto, actor y fin de la economía. (Ley 454/1998, art. 2).

Aun cuando las acciones cooperadas - o solidarias- se remontarían al inicio de la humanidad, los orígenes del cooperativismo moderno se pueden ubicar en la época la revolución industrial.

El movimiento cooperativo parte de la economía solidaria, se basa en valores puntuales: solidaridad, cooperación, ayuda mutua, reciprocidad, equidad, responsabilidad participativa y cuidado del medio ambiente. Hoy en día, se reconocen cinco tipos de cooperativas: precooperativas, multiactivas, integrales, de trabajo asociado y especializadas. En esteúltimo sector, se ubican las cooperativas de ahorro y crédito, cuyo objeto social está en suplir las necesidades financieras de los socios y terceros.

Al revisar la historia del cooperativismo en Colombia, se encuentra que el jurisconsulto colombiano Rafael Uribe Uribe plantó «las ideas cooperativas como parte de su pensamiento sobre el socialismo democrático de corte humanístico, en octubre de 1904» (Uribe, 26 mayo 1997). En 1916, se propuso el primer proyecto de legislación cooperativa. Hacia 1920, el presbítero boyacense Adán Puerto Sánchez se dedicó a difundir el pensamiento cooperativo. En 1931, el Congreso de la República aprobó la primera ley cooperativa (Ley 134). En 1963, se expidió el Decreto 1598, el cual introdujo el concepto de la especialización de las cooperativas, entre ellas, las de ahorro y crédito (Cooptenjo, s. f.). En Colombia, la 
economía solidaria se encuentra regulada por La Ley 454 de 1998, y el Decreto 1134 de 1989 se constituye en el marco legal de las cooperativas de ahorro y crédito.

Colombia cuenta con una diversa gama de cooperativas que van desde las dedicadas a la actividad financiera hasta las de actividad aseguradora. En cuantías, a diciembre de 2014, un poco más de $12 \%$ de la población colombiana se encontraba afiliada a las más de 4000 cooperativas existentes; de estas, 75 se encontraban en Boyacá, distribuidas en 51 de los 123 municipios que componen el departamento (Confecoop, 2014, pp. 9-10, 15). La Cooperativa de Comerciantes Comerciacoop, especializada en ahorro y crédito, fundada en Chiquinquirá en 1996, se cuenta como un ejemplo de las cooperativas boyacenses especializadas en ahorro y crédito (Figura 1).

Figura 1. Logo 20 años Comerciacoop.

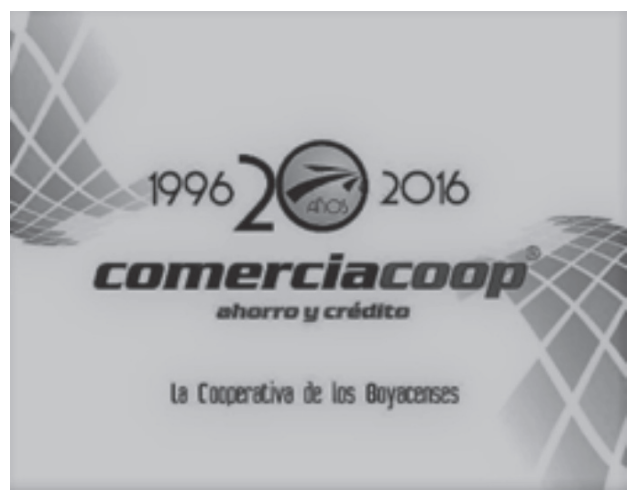

Fuente. Comerciacoop (s.f).

Comerciacoop tiene como misión «dinamizar cultura de confianza, que propicie el crecimiento económico a través del ahorro, crédito y opciones microfinancieras, de manera ágil, que conlleve el bienestar de los asociados» (Comerciacoop, Misión y visión). En su plan estratégico, plantea como visión «ser al 2016 la cooperativa modelo de microfinanzas de los boyacenses» (Comerciacoop, Misión y visión). A su vez, su objeto social pretende promover el desarrollo empresarial y la cultura solidaria, incrementando constantemente la base social y su capital de trabajo para garantizar a través de sus servicios, la satisfacción de las necesidades de sus asociados $y$, de esta manera, contribuir al bienestar económico y social, y al desarrollo regional. (Comerciacoop, Objeto social).

Por otra parte, si se acepta que la historia empresarial se constituye en una alternativa de investigación en la administración de empresas, a su vez se ha de reconocer como una disciplina destinada a investigar acerca de la empresa desde un punto de vista dinámico que tiene en cuenta los factores de cambio y la evolución de las organizaciones y de los empresarios investigados. De esta manera, la Universidad Pedagógica y Tecnológica de Colombia ve la necesidad de contribuir a la configuración de la historia empresarial de los boyacenses, y en consecuencia, la Escuela de Administración de Empresas de la Sede Seccional Chiquinquirá, de la historia empresarial de la ciudad.

Los anteriores elementos conformaron un campo susceptible de investigar desde la historia empresarial a partir de una pregunta específica: en sus 20 años de existencia, ¿qué factores administrativos han posibilitado el crecimiento económico, el desarrollo empresarial y el cumplimiento de la función social de Comerciacoop? Tal proceso de investigación se propuso, como objetivo principal, realizar la historia empresarial de los 20 años de Comerciacoop. Para ello, se establecieron como objetivos específicos: periodizar los acontecimientos que han influido en el crecimiento económico y en 
el desarrollo empresarial de Comerciacoop, determinar el papel cumplido por Jesús María Medina Durán como gestor y director de los procesos administrativos de Comerciacoop y analizar los procesos administrativos llevados a cabo en Comerciacoop que han permitido evolucionar en cuanto a sus condiciones sociales y organizacionales.

\section{Metodología}

\subsection{El método y las técnicas}

La historia empresarial hace parte de la investigación histórica, y su objeto está relacionado con el concepto de acontecimientos empresariales. Las unidades de análisis en este campo han sido, por una parte, la empresa y el empresario y, por otra, el empresariado, entendido como un conjunto compuesto por la actividad empresarial y sus protagonistas (Roncancio, 2016, pp. 36-40).

En la historia empresarial, se estudia el empresario como un agente dinámico, creador, gestor e inversionista; y a la empresa como la forma de organizar las distintas actividades empresariales. Dávila Ladrón de Guevara Ladrón de Guevara (2005) señala que del empresariado se estudian los "procesos económicos y sociales relacionados con los orígenes, funciones, estructura, estrategias, trayectoria y desempeño", en diferentes unidades de análisis: "empresas específicas (privadas, estatales y mixtas) en diferentes sectores de la economía, empresarios (individuos) en diferentes sectores económicos (industria manufacturera, comercio, sector agrícola, finanzas, minería, etc.), familias empresariales, grupos económicos, asociaciones de empresarios e instituciones para la educación de empresarios y de sus cuadros directivos. (pp. 64-65).
La historia empresarial no solo estudia actores, sino también acciones empresariales. Así, se identifica el objeto de estudio de la historia empresarial como actividad empresarial en el tiempo. A su vez, la actividad empresarial se define como «la actividad deliberada [...] de un individuo o grupo de individuos asociados, emprendida para iniciar, mantener o ampliar un negocio orientado al beneficio para la producción o distribución de bienes y servicios económicos» (Cochran, citado por Betancourt, 2003, p. 200).

El estudio histórico de la empresa permite acercarse a «élites, familias y grupos que han transitado el camino hacia el éxito, fracaso o quiebra en sus actuaciones económicas, lo cual también constituye historicidad» (Ordóñez, 2012, p. 29). En estas unidades de análisis de la historia empresarial, se puede ver el rol del empresario como administrador, gestor, director y gerente de las organizaciones empresariales. Se analizan sus funciones dentro de la empresa, porque es su trabajo, y su trabajo es parte de su historia de vida. De este modo, la historia empresarial «debe ser comprendida como el estudio analítico de los cambios experimentados por la empresa en sus sistemas de producción, comercialización y dirección a lo largo del tiempo» (Romero, 2003, p. 821). En esos cambios, las decisiones de la administración tendrán un papel protagónico: las políticas y las estrategias de las empresas modifican los estados de las diferentes áreas y dirigen su funcionamiento. 
En ese orden de ideas, la historia empresarial también permite visualizar la dinámica de las organizaciones y el papel que cumple la administración en ese proceso.

Por otra parte, se ha de reconocer que la historia empresarial, aun cuando comparte un enfoque común con otras ciencias sociales, su epistemología y su metodología concuerdan con la corriente central de la historia. Por tal razón, «ha adoptado las herramientas que aquella ha desarrollado, como la crítica de fuentes, la historia oral, entre otras» (Zuluaga, 2010, p. 4). De ahí que la historia empresarial acuda a particulares fuentes de investigación. Para Dávila Ladrón de Guevara,

la acuciosidad de los investigadores ha demostrado el valor de las fuentes notariales, informes oficiales y registros públicos, así como de una amplia gama de fuentes documentales (memorias, archivos de prensa, fuentes secundarias, etc.). Y para los estudios que cubren la época contemporánea las entrevistas en profundidad han comprobado ser una fuente muy valiosa y útil, (2005, p. 66).

Los archivos se convierten en fuentes relevantes de información para la historia empresarial; asimismo, la información puede provenir de la prensa, los estudios de mercado, los diagnósticos empresariales, las campañas publicitarias o los informes del sector.

Además, la entrevista, con los protagonistas, se constituye en otra fuente de información para la historia empresarial. Una razón para tomar en cuenta esta fuente radica en que no toda la información se registra en documentos, sino que mucha queda en la memoria de las personas y se transmite de manera informal a través de expresiones orales -la historia oral como fuente alternativa-. La oralidad en las organizaciones hace parte de la comunicación informal; su función es transmitir una parte de la memoria organizativa como producto de las evocaciones de las personas (Ordóñez, 2012, p. 25) (Figura 2).

Figura 2. Entrevista al gerente fundador de Comerciacoop.

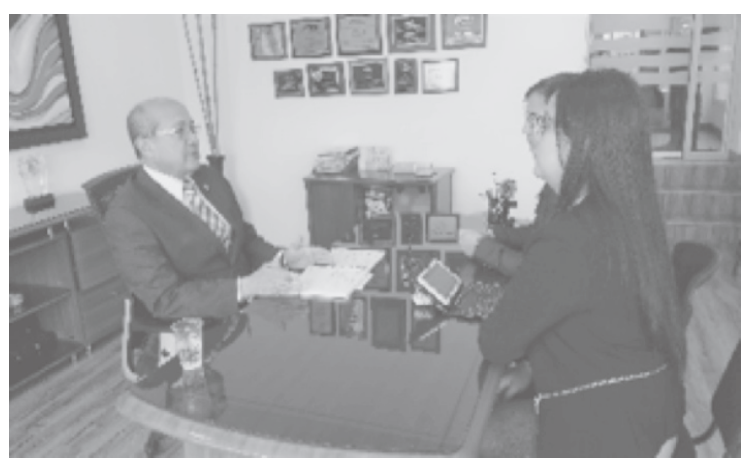

Fuente. Elaboración propia.

Por su parte, la historia de vida se define como -la forma en que una persona narra de manera profunda las experiencias de vida en función de la interpretación que esta le haya dado a su vida y el significado que se tenga de una interacción social- (Chárriez, 2012, p. 53). Mediante la historia de vida, la historia empresarial puede aprender, a partir de las experiencias del empresario, acerca de la situación económica, social, política y empresarial del entorno de vida de esa persona.

El investigador en historia empresarial recurre a la entrevista como fuente para la historia de vida. Así, puede conocer en detalle las interpretaciones que el hombre organizacional da a los momentos que ha vivido; para ello, el entrevistador, mediante entrevistas sucesivas, «obtiene el testimonio 
de los acontecimientos y valoraciones de su propia existencia» (Chárriez, 2012, p. 53). La entrevista que se realiza dentro de la historia de vida es abierta, no estructurada, tiene «forma dialógica», permite un «evento interactivo» (Mallimaci y Giménez, 2006, p. 174). No se busca que el empresario o directivo relate en forma cronológica exacta sus experiencias, sino que mediante diálogos espontáneos recuerda hechos significativos, no necesariamente organizados en una línea de tiempo (p. 179).

Las fuentes archivísticas también tienen un papel importante en la historia de vida: «Es importante recolectar todo tipo de testimonios y hechos de vida, sean escritos, visuales o relacionales, a fin de completar y enriquecer el relato» (p. 199).

\subsection{Los pasos}

Para la investigación que sustenta este artículo, se consideraron tres pasos esenciales: i) la recolección, ii) la sistematización y el análisis de la información y iii) la escritura de los informes.

\subsubsection{Primera fase, la recolección de información}

Para cumplir con la primera etapa, se acudió a la información que Comerciacoop guarda en sus archivos, es decir, se tomaron fuentes primarias como actas y reportes que toda sociedad formalmente constituida está obligada a suministrar a la Administración pública; de igual manera, se consultaron los documentos de administración de la sociedad: manuales de organización del trabajo, los informes financieros de Comerciacoop -sin olvidar la correspondencia interempresarios, interempresa o intergremios-.
Los cánones del método histórico demandan que, antes del análisis de la información, se debe confrontar la validez del documento, de la fuente estudiada. Esto en razón de que, a pesar de que un documento registre un acontecimiento, no implica, necesariamente, que se convierta en fuente para su corroboración; en otras palabras, un documento distante en el tiempo debe ser tomado con sumo cuidado para que, en realidad, se pueda usar como fuente primaria de lo estudiado. Sin embargo, en el estudio adelantado, no se consideró necesario contrastar la validez de las fuentes, pues la información se tomó directamente de los archivos institucionales. En la investigación adelantada, no existió tal distancia en el tiempo, pues, a pesar de que la cooperativa cumple 20 años, aún se encuentra vigente y los archivos se actualizan permanentemente con el propósito que se le da a un archivo en una empresa en funcionamiento.

La entrevista con los protagonistas fue determinante en la investigación. La conversación con las personas involucradas en el hecho se constituyó en fuente de información para la investigación. Al res-pecto, se debe señalar que el fundador de la cooperativa aún se encuentra al frente de ella. Además, gran cantidad de los procesos administrativos de Comerciacoop -en especial, los de los primeros años - no están registrados en documentos; por tanto, se tuvo que acudir a la memoria de las personas que han estado vinculadas a Comerciacoop desde su fundación, de quienes aún se encontraban vinculados en el momento de la investigación (ver Entrevistas).

En ese sentido, además de emplear entrevistas en profundidad con Jesús María Medina Durán, se realizaron entrevistas estructuradas tanto a las personas que lo 
acompañaron desde el principio como a quienes han acompañado durante varios años el proceso administrativo de Comerciacoop. Asimismo, se organizaron sesiones de trabajo para entrevistar, con cuestionarios semiestructurados, a funcionarios de alta gerencia, rango medio y empleados de base. De igual manera, se recurrió a archivos fotográficos y mecánicos -grabaciones de entrevistas y reuniones- y a publicaciones institucionales -informes de gestión y folletos publicitarios-.

\subsubsection{Segunda fase, la sistematización y el análisis}

La información recolectada se sistematizó mediante matrices que permitieron relacionar los momentos históricos con las teorías administrativas. En esta fase, el análisis se tomó como el "conjunto de operaciones empírico-conceptuales mediante las cuales se construyen y procesan los datos pertinentes del problema de estudio para ser interpretados" (Torres, 2002, p. 167).

Este análisis se realizó con el fin de determinar, desde la administración, tanto los aspectos económicos de la organización como la complejidad del trabajo de la empresa con el fin de cumplir su función, la importancia de las personas en la actividad empresarial y la función y el rol de la administración en la cooperativa.

Este análisis permitió interpretar la evolución de la organización como tránsito de un estado socioorganizacional a otro y el de su administración como generadora de cambios; solo así se podía «rescatar el papel de la administración como generadora de cambios o creadora de historia» (Roncancio, 2016, p. 53). En consecuencia, se recuerda que los sucesos ocurridos en la Comerciacoop deben tener en cuenta la organización en función de criterios como las áreas funcionales, el proceso administrativo, los recursos, los niveles organizacionales, las prácticas administrativas, etc.

\subsubsection{Tercera fase, la escritura de documentos}

En la escritura del informe final, además de considerar los requisitos formales de un texto académico científico, se estructuró un esquema que atendiera una «línea de argumentación que [recogiera] y [estuviera] sustentada por argumentos expositivos y explicativos en torno a una formulación temática y las partes específicas de aquello que se quiere exponer a la atención del lector(a)» (Fernández, 2010, p. 10).

En ese instante, se recordó que el modelo tradicional «de escribir la historia empresarial ha sido la narración, la descripción sistemática de un tema histórico como la empresa, el empresario» (Roberts, 2001, p. 164). Sin embargo, la simple narración de eventos en el curso del tiempo necesita algo más para elevar la historia a la categoría de ciencia: se debe apuntar «a un tipo de discurso científico y explicativo, producto de la actuación investigativa rigurosa» en un todo significativo que responda al qué, por qué o cómo de un estado o de un cambio (Betancourt, 2003, p. 208). Los textos de la historiografía empresarial han de mostrar la complejidad de la realidad. Desde tal perspectiva, la historia de Comerciacoop se presenta a continuación. 


\section{Resultados}

\subsection{El contexto}

La segunda mitad de la década de 1990 será recordada en la historia financiera de Colombia como la época de la gran crisis. Esta consistió en el estancamiento en ciertos sectores económicos y la presencia de cifras negativas en otros. La crisis tuvo como principales características el aumento del desempleo, el crecimiento de la cartera vencida del sistema bancario, el retroceso tanto en las ventas para los comerciantes como en las exportaciones y la reducción en varios indicadores económicos; asimismo, el PIB nacional se redujo abruptamente en el último quinquenio de la década. A lo largo de la década, los síntomas se fueron acumulando y la crisis que se ubicó, de manera notoria, en el lapso entre 1996 y 1997 (Valderrama, 1999, pp. 242-243).

Por su parte, la crisis del sector bancario de la década de 1990 se hizo evidente cuando las cooperativas financieras empezaron a parecerse a bancos sin serlo en realidad. Las cooperativas de ahorro y crédito creyeron, en principio, que no serían afectadas de manera directa por tal crisis. Sin embargo,

el sector solidario pasó de ser una pieza fundamental en el desarrollo regional del país, en los tiempos de la apertura económica, para convertirse ahora en una cenicienta con la que nadie quiere tener relaciones. En realidad los cooperativistas están pasando su mala hora: las corporaciones financieras se niegan a respaldarlos con créditos, el sector público no quiere realizar inversiones en sus oficinas, las aseguradoras tienen recelo a respaldar su actividad y como si fuera poco los socios y ahorradores están retirando sus depósitos. (El Tiempo, 23 marzo 1998).

Para ese entonces, no fue extraña una generalizada desconfianza en las instituciones financieras, en especial en las cooperativas. Más aún cuando existían expectativas desfavorables acerca del desempeño de la economía colombiana. La desconfianza y las bajas expectativas frente al sistema financiero colombiano llevaron a la expedición, por parte del Estado, de medidas para enfrentar la crisis, las cuales se iniciaron con el establecimiento de la emergencia económica para apoyar el sistema hipotecario y cooperativo. Ello incluyó la expedición de la Ley 454 de 1998 que

estableció las bases del sector cooperativo moderno en Colombia, facultó al Estado y al sector para lograr la reestructuración y fortalecer los esquemas de control y promoción de las cooperativas. Gracias a esta medida, las cooperativas cuentan con una estructura institucional fuerte y un sector solvente y sólido. (Arango, 2006, p. 34)

\subsection{El empresario Jesús María Medina Durán}

Huilense nacido en 1948 en el municipio de Teruel. El cuarto de nueve hermanos, hijo de don Mateo y doña Sara, miembro de una familia humilde dedicada a las labores del campo, devota y trabajadora. Sus 
primeros años de vida trascurrieron entre el aprendizaje de las primeras letras en la escuela del municipio y el desplazamiento forzoso del cual fue objeto su familia debido a la violencia partidista que por esos días azotaba al país.

En su transcurrir por la academia, estuvo en varios colegios, por ejemplo el PreSeminario San Luis Gonzaga (Mesa de Elías, Huila) y el Seminario Conciliar María Inmaculada de la Diócesis de Garzón. Estos dos planteles educativos encaminaban su futuro por la vida sacerdotal. Una vez descartada la posibilidad de su sacerdocio, al terminar sus estudios de bachillerato en el Colegio -Instituto- Ciudad de Neiva, cumplió con el servicio militar durante 1968. Al culminar esta etapa, se convirtió en profesor en comisión, nombrado por la Secretaría Departamental de Educación, en el Colegio Concentración Rural Jorge Villamil Ortega de la Federación Nacional de Cafeteros en Gigante, en el centro-oriente del departamento.

Luego de unos meses de impartir clases, tras una convocatoria de la Caja Agraria, se vinculó en 1969 como inspector avaluador. Esta institución bancaria lo asignó, en principio, a Timaná -Huila-; sin embargo, por razones administrativas, fue enviado a Muzo -Boyacá-, ubicado en el occidente del departamento.

Durante el tiempo trabajado en la Caja Agraria, recorrió gran parte del departamento de Boyacá. En distintos lugares en los que estuvo, afrontó diferentes retos propios de su trabajo; primero como inspector avaluador, luego como promotor de desarrollo, por último, como director de oficina.
Paralelo a su transcurrir por la Caja Agraria, dos hechos importantes marcarían el rumbo en su vida: el primero, el matrimonio con la señora María Julia Barajas, en 1972 -matrimonio del cual nacieron dos hijos, Mario Fernando, en 1973, y Diana Carolina, en 1978-; el segundo, su ingreso a la Universidad Pedagógica y Tecnológica de Colombia en Tunja donde estudió Administración de Empresas, estudios que culminó en 1982.

Tras haber trabajado veinticuatro años en la Caja Agraria -donde hizo carrera, al pasar de inspector avaluador a gerente de oficina-, en 1993, en el periodo en que se dio el cierre de esta entidad, Jesús Medina se acogió a un programa de pensiones que propuso el Gobierno nacional. Una vez pensionado, con la experiencia adquirida en esos años, se vinculó en 1994 a la Fundación Unidad de Asistencia Técnica Tunja, en la cual impartió varias capacitaciones, como un taller de finanzas en la sede de la Caja de Compensación Familiar de Boyacá.

El trabajo en esta fundación le brindó la oportunidad de conocer al entonces gerente de la Caja Popular Cooperativa en Chiquinquirá, Néstor Medina, de quien fuera sucesor tiempo después gracias a la recomendación hecha por la directora de aquella fundación al gerente nacional de la Caja Popular Cooperativa, en su momento Jorge Moreno Ojeda. Una vez vinculado a esta cooperativa como gerente de la oficina de Chiquinquirá, tomó un taller de reprogramación neurolingüística ofrecido en Paipa por la misma entidad para sus trabajadores. Este evento, denominado "Caminos", fue crucial para sus futuras aspiraciones de crear empresa: redundaría en la idea de creación de un ente de tipo financiero que operara desde Chiquinquirá. 
Luego de 20 años de gerencia de Comerciacoop, Jesús Medina

ha vislumbrado situaciones clave $y$, junto con el Consejo Administrativo y con sus colaboradores, ha tomado decisiones e incluso riesgos que se reconocen como hechos trascendentales que se han convertido en punto de quiebre con los cuales se han marcado un antes y un después en el encadenamiento de hechos significativos. (Molina, 2016, p. 11).

\subsection{Los inicios de Comer- ciacoop (1996-1999)}

Después de darse a conocer en la comunidad chiquinquireña, Jesús Medina fue vinculado a la Unión de Comerciantes y Profesiones Independientes, primero como invitado y luego como tesorero de la entidad. Esta agremiación se había conformado a comienzos de la década de 1990 en Chiquinquirá. Su fin consistía en fortalecer el comercio en la Ciudad Promesa de Colombia; para ello, procuraba participar en diversas actividades sociales, económicas e, incluso, de carácter político. En este último sentido, decidieron apoyar al entonces candidato Jaime Enrique Ortiz Franco, quien aspiraba a ser electo alcalde municipal; así mismo, brindaron su apoyo a Orlando Forero como aspirante al Concejo Municipal. Los resultados electorales dieron frutos positivos, y en 1996 Jaime Ortiz fue electo alcalde; y Orlando Forero, concejal.

Había, entonces, cierta euforia de poder en la Unión de Comerciantes y Profesiones Independientes, circunstancia aprovechada por Jesús Medina. Luego de varias reuniones con los integrantes de esta agremiación, logró implantar la idea de creación de una empresa que estuviera al servicio de la comunidad, objetivo que se había trazado en el taller "Caminos" de la Caja Popular. En una reunión adelantada en el Hotel Sarabita por la Unión de Comerciantes y Profesiones Independientes julio de 1996, ante algunos de los comerciantes agremiados, Jesús Media expuso una vez más su idea de crear una empresa en el sector financiero. Comentó la propuesta de crear un banco de comerciantes y pidió que lo apoyaran. La invitación fue oída con seriedad y se citó a una reunión formal de la Unión de Comerciantes y Profesiones Independientes. En esa reunión, el primer tema en la agenda consistió en escuchar la propuesta de Jesús Medina.

Los comerciantes agremiados de la ciudad de Chiquinquirá de la época creyeron en la idea de establecer un negocio con el fin de prestar dinero $y$, de este modo, obtener una ganancia de dicha transacción. La idea de negocio era clara; sin embargo, no se sabía a ciencia cierta qué tipo de empresa se establecería. Si bien es cierto que Jesús Medina era el gerente de la oficina en Chiquinquirá de la Caja Popular Cooperativa, entidad de orden cooperativo, también era cierto que poseía poco conocimiento acerca del cooperativismo. Fue contratado como gerente de una entidad financiera $y$, en el transcurso de su dirección, breve, por cierto, desde las altas directivas de la Caja no se hizo énfasis en el carácter cooperativo de esta. Los cocimientos de cooperativismo en esa época se basaban en lo recibido en las clases del profesor José del Carmen Oviedo Barrera, que le permitieron obtener el título de Administrador de Empresas de la Universidad Pedagógica y Tecnológica de Colombia.

En el transcurso de las reuniones de la agremiación, Jesús Medina concluyó que el 
modelo que más se ajustaría a la naciente empresa sería el de una cooperativa. Pero hasta ese momento no se estaba planteando ninguna necesidad de nadie, lo que la constituiría en un caso atípico de cooperativa. Esta nueva cooperativa no se formaría por una necesidad; solo se aprovecharía una coyuntura, una oportunidad, respaldada por comerciantes agremiados de Chiquinquirá.

En la década de 1990, el ambiente financiero que rodeaba a Comerciacoop, justo en el momento de su creación, no era del todo halagüeño. Fue en ese medio de incertidumbre donde, precisamente, empezaría a funcionar Comerciacoop como una cooperativa de ahorro y crédito. Todo apuntaba, entonces, a una corta existencia de la cooperativa. Para contrarrestar el clima adverso, los comerciantes reconocieron la necesidad de profundizar en conocimientos en el manejo administrativo de cooperativas. Por ello, durante el periodo de incubación, recibieron capacitaciones por parte del Servicio Nacional de Aprendizaje (SENA) y, una vez creada la cooperativa, realizaron pasantías en otras cooperativas -como Cooperamos de la ciudad de Ibagué-.

En los meses posteriores a julio de 1996, Jesús Medina realizó acercamientos para conseguir la capacitación con el SENA en cuanto a los fundamentos del cooperativismo. En ese momento, Orlando Rodríguez era contratista de esta entidad y aceptó impartir una capacitación en cooperativismo básico. En efecto, se realizaron las clases de manera regular durante los sábados y domingos en agosto y septiembre. A este evento asistieron de manera masiva los integrantes de la Unión de Comerciantes y Profesiones Independientes, aun cuando algunos todavía eran muy escépticos y temerosos debido a que en el momento el sector financiero contaba con muy poca credibilidad.
El instructor aprovechó su condición para darle un giro a la idea inicial de Jesús Medina y quiso precipitar la fundación de la cooperativa, en un intento por retirar de la dirección al creador de la propuesta. Además de configurar el manual de crédito, convocó a una asamblea a la cual asistieron aproximadamente treinta personas. Ante la intención de fundar la cooperativa sin la presencia de Jesús Medina, fueron los mismos comerciantes quienes informaron a Medina el suceso, quien regresó a Chiquinquirá para estar presente en la asamblea citada por Rodríguez. Una vez iniciada la reunión, uno de los asistentes y miembro fundador de la cooperativa, Alfonso María Sierra, tomó la palabra y se dirigió a los presentes en la reunión para afirmar que la cooperativa se crearía solo si Jesús Medina era el gerente.

Este hecho sirvió para que Jesús Medina tomará definitivamente el liderazgo. Una de las primeras acciones fue la de contactar directamente al SENA Chiquinquirá. En una reunión con Egidio Cardozo, se acordó que el SENA brindaría un seminario en planeamiento estratégico. Como consecuencia de los talleres adelantados, se definió la imagen corporativa, se establecieron los objetivos, el objeto social, los colores que identificarían a la cooperativa -azul, blanco y rojo, como la bandera de Chiquinquirá-. En cuanto al nombre que tendría la cooperativa, algunos propusieron que debía llamarse Comecoop, pero ese nombre ya se encontraba inscrito en la Cámara de Comercio, por lo cual el señor Hermes Cristancho sugirió que se llamara Banco del Occidente. Al final, la propuesta de Jesús Medina que se llamara Comerciacoop tuvo mayor acogida, pues con este rótulo se identificaría el sector de comerciantes de Chiquinquirá. 
Posteriormente, se creó el comité de organización para la fundación de la cooperativa: este nuevo organismo se encargó de desarrollar las capacitaciones acerca de financiación de la entidad. En una de tales sesiones de capacitación, Egidio Cardozo invitó a Jesús Medina para que hiciera una intervención. Medina, en su arenga, habló de la importancia de fundar empresa apoyada por comerciantes y de fundar una empresa que «hoy hablara de millones para mañana hablar de billones», y fue así como quedó definido que el aporte social inicial fuera de un millón de pesos para poder ser asociado de Comerciacoop.

En ese proceso que estaba convirtiendo realidad su idea primigenia, Jesús Medina contó con el respaldo de varias personas, pero se debe resaltar, en especial, la colaboración de Gloria Carmenza Lancheros Campos, quien para 1996 se desempeñaba como secretaria de la Unión de Comerciantes y Profesiones Independientes. En el momento de la euforia de la creación del "Banco de los Comerciantes", que terminó por llamarse Comerciacoop, Gloria Carmenza Lancheros inició el proceso de recolección del dinero para vincular a los futuros asociados a la nueva cooperativa. Para registrar los aportes parciales o totales, se valió de una herramienta muy tradicional para el recaudo de dinero: un recibo de caja forma minerva.

Una vez establecidas las condiciones para asociarse, se continuó con el proceso de capacitación. El entusiasmo fue tal que se inició la organización de los documentos de fundación de la cooperativa y se realizó la convocatoria de la primera asamblea. Jesús Medina solicitó asesoría de Óscar Olarte y Héctor Rojas. Dicha reunión se adelantó en las instalaciones del Consejo Municipal. Posteriormente, se realizó una reunión en el Hotel Sarabita para aprobar los estatutos de la cooperativa; sin embargo, por inconsistencias de redacción, en esa reunión no se aprobaron los estatutos. Después, se propuso que fuera el jueves 24 de octubre de 1996 la fecha de fundación de la Cooperativa de Comerciantes Comerciacoop (Figura 3).

Figura 3. Reunión de asociados fundadores en julio de 2016.

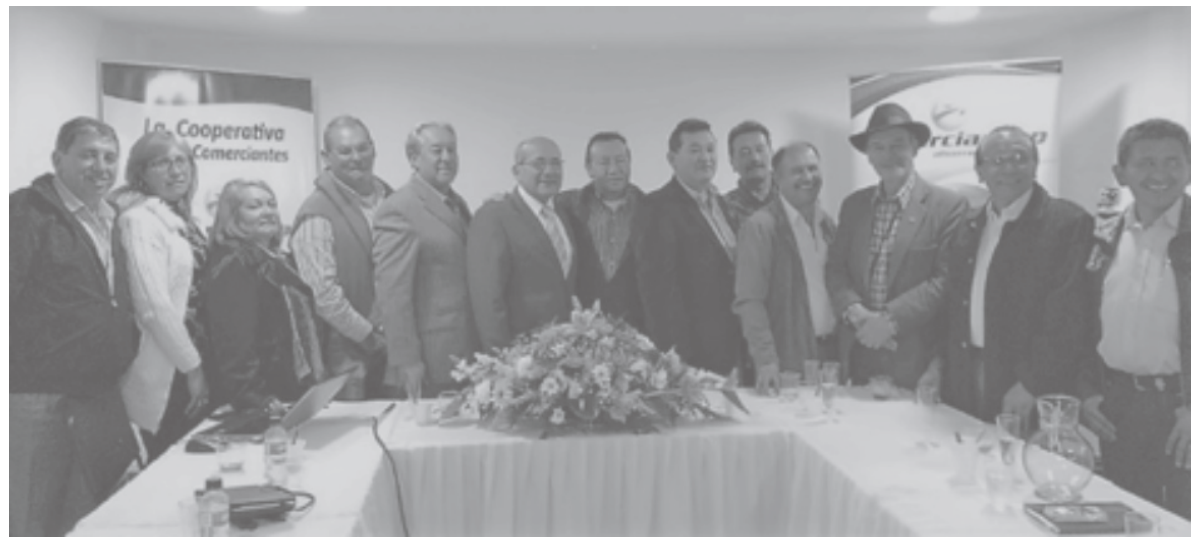

Fuente. Elaboración propia. 
La asamblea de fundación se llevó a cabo en el Club del Comercio con una logística que resultó insuficiente: la cantidad de asistentes fue mucho mayor de la esperada. En la reunión, Gloria Carmenza Lancheros se encargó de recibir los aportes en efectivo. En medio de la euforia de esa primera asamblea, solo 85 de los presentes firmaron el acta de fundación y se alcanzó un aporte social inicial de $\$ 22$ 750 00; así mismo, se nombraron cuadros directivos y se efectuó su toma de juramento.

Posteriormente, se realizó una reunión, ya de asociados, en el Hotel Sarabita a fin de nombrar el gerente de Comerciacoop; para ello, se designó a Jesús Medina, con quien en ese día se estableció un contrato verbal de trabajo. En diciembre, Medina se retiró de la Caja Popular Cooperativa y se dedicó de tiempo completo a Comerciacoop. Al finalizar 1996, se presentaron los documentos al Departamento Administrativo Nacional de Cooperativas, para lograr la autorización del ejercicio de actividad de ahorro y crédito y, de esta forma, empezar en forma legal con el funcionamiento de Comerciacoop.

Las primeras actividades de Comerciacop se llevaron a cabo en las antiguas bodegas del Almacén Mío, con ayuda del comerciante Dídibo Cabieles, quien facilitó los muebles de la Unión de Comerciantes y Profesiones Independientes a la naciente cooperativa. La principal actividad de Comerciacoop consistía en el préstamo de dinero; sin embargo, fue tal la demanda que empezó a escasear el efectivo, a pesar de que ya se había empezado a captar dinero por ahorro. Luego de unos días de funcionamiento, se agregó una estrategia de negocio en búsqueda de tener alta liquidez. Para ello, se recurrió a la figura del cambio de cheques a uno o dos días y a la de créditos a muy corto plazo sobre la base de la confianza en las personas.
El 27 de enero de 1997, dicho departamento autorizó a Comerciacoop el ejercicio de actividad de ahorro y crédito mediante el Auto 004. Así, el 15 de febrero de ese mismo año se abrió la primera oficina de Comerciacoop en un local ubicado en la carrera 10 \# 17-52 de Chiquinquirá. Unos días antes de la apertura de la oficina, se adquirieron algunos muebles básicos para los empleados, la gerencia y la atención al público. La estructura organizacional que tenía Comerciacoop en su inicio estaba conformada por el gerente Jesús Medina, la secretaria Miriam Amalia Reyes y la auxiliar Teresa Ortiz. Durante seis meses, aproximadamente, la estructura organizacional se mantuvo intacta; pero ahora se contaba con Gloria Carmenza Lancheros como Secretaria y Liliana Pineda como auxiliar.

Dada la crisis del sector cooperativo de 1998, el Gobierno nacional expidió la Ley 454/1998. Con el artículo 42, se obligaba a las cooperativas financieras a contar con un capital inicial de $\$ 500000000$. Comerciacoop no poseía ese capital. Esto obligó al gerente a presentar a la Superintendencia de Economía Solidaria (SES) una solicitud de excepción a montos mínimos.

Como puede deducirse, el panorama no era favorable. Jesús Medina recurrió a una estrategia, si se quiere, académica: dirigió la organización sucesiva de dos coloquios de economía solidaria en Chiquinquirá (1998 y 1999). A estos eventos fueron invitados altos dignatarios del sector cooperativo e, incluso, del Gobierno central. Entre los asistentes, se contó con la presencia de directores y gerentes del SENA, del Departamento Administrativo Nacional de la Economía Solidaria, de la Asociación Colombiana de Cooperativas, la SES y, particularmente en 1999, del ministro de Hacienda de ese entonces, Juan Camilo Restrepo. 
Esta estrategia hizo visible a Comerciacoop, de ahí que la SES, al conocer la petición de apertura con montos mínimos, consideró pertinente otorgar la autorización en condición de excepción para el ejercicio de la actividad de ahorro y crédito.

\subsection{Consolidación (2000-2009)}

A partir de 2000, Comerciacoop inició un proceso de mercadeo con mayor fuerza de la que se venía adelantando. En ese año, fue representativo para Comerciacoop la expedición, por parte de la SES, de la Resolución 0188 del 16 de mayo. El 31 de mayo se realizó la inscripción al Fondo de Garantías de Entidades Cooperativas y el 31 de octubre se obtuvo la certificación plena por parte de esta entidad. Para 2004, luego de un periodo lento de crecimiento, tuvo lugar un aumento significativo no solo en el número de asociados, sino también, y de manera un poco preocupante, en los pasivos.

Comoestrategia, para2005,Comerciacoop se orientó al apoyo de los microempresarios a través de las microfinanzas con metodologías aportadas por el Consejo Mundial de las Cooperativas de Ahorro y Crédito (WOCCU) $\mathrm{y}$, posteriormente, apoyadas por el Fondo Emprender y con recursos del Colombiano de Modernización y Desarrollo Tecnológico de las Micro, Pequeñas y Medianas Empresas y de la Confederación de Cooperativas de Colombia.

Por iniciativa del gerente, luego de asistir a diversos eventos del cooperativismo donde se daba a conocer la existencia de Comerciacoop, se obtuvo apoyo de la Banca de las Oportunidades del Banco de Desarrollo Empresarial y Comercio Exterior de Colombia. Gracias a tal apoyo, se obtuvo la asesoría del WOCCU que le permitió a Comerciacoop conocer la estructura de la "cooperativa modelo" y los indicadores PEARLS (estos posibilitan medir el rendimiento de las cooperativas de ahorro y crédito); así, se generó una estructura organizacional más sólida.

En septiembre de 2008, Comerciacoop obtuvo, por parte de la SES, la autorización para ejercer actividad financiera en el ámbito nacional. En 2009, tras haber mejorado las condiciones locativas y de infraestructura -cambios requeridos dado el crecimiento tanto en el número de asociados como en el de empleados-, Comerciacoop dio comienzo a un proceso continuo de expansión que redundaría en ofrecer una red de oficinas y corresponsales: Comerciacoop dio apertura al primer corresponsal bancario en el sector cooperativo colombiano. Este punto de atención se ubicó en Villa de Leyva, provincia de Ricaurte, como resultado de la alianza estratégica establecida con la Cooperativa Multiactiva Coomexa O. C.

\subsection{Expansión (2010-2016)}

Comerciacoop dio paso a una fase de expansión de sus oficinas a diferentes municipios del departamento de Boyacá. Entre 2010 y 2015, abrió oficinas en Tunja y Garagoa, el corresponsal de Villa de Leyva pasó a ser oficina y se abrieron corresponsales no bancarios en Guateque, Otanche, Arcabuco; asimismo, una extensión de caja al centro de acopio y mercadeo de Chiquinquirá.

En 2015, se creó la unidad de microfinanzas, con el fin de tener un área especializada en el tema. Además, se realizaron algunas modificaciones a la planta de personal, cambios aprobados por el Consejo de 
Administración en el año inmediatamente anterior. Como resultado, se dio lugar a un nuevo organigrama y una escala salarial estructurada.

Para 2016, se abrió el corresponsal y punto de atención en Ráquira, en este año se intensificaron los esfuerzos de Comerciacoop con el fin de poder ingresar a la convocatoria realizada por el Gobierno nacional con el objetivo de llegar al sector agropecuario y llevar a ese ámbito la enseñanza de la cultura financiera a las zonas marginales del campo.

Un breve balance cuantitativo de los veinte años de Comerciacoop (1996-2016) evidencia el crecimiento de la entidad. Por una parte, al cierre de 1996 contaba con 116 asociados, un activo de $\$ 125$ millones, un pasivo de $\$ 124000$ y un patrimonio total de $\$ 125$ millones. Según la Subgerencia Administrativa y Financiera, en septiembre de 2016, la base social de Comerciacoop estaba constituida por 11116 asociados; en agosto de ese mismo año, sumaba $\$ 23$ 113 millones en activos, \$16 459 millones en pasivos y un patrimonio de $\$ 6564$ millones (Coomerciacoop en cifras, 2016, pp. 38-39). Al cierre 2015, Coomerciacoop movilizó en créditos recursos por valor $\$ 22.8$ mil millones; con 2216 operaciones en microcrédito, 850 en crédito comercial y 1307 en crédito de consumo (Comerciacoop, Ahorro y crédito, 2016, p. 25).

Así mismo, en 1997, la estructura orga-nizacional estaba compuesta por tres personas; a finales de 2015, "la Cooperativa tenía una planta de personal con 52 trabajadores, de los cuales 34 se encontraban vinculados mediante contrato de trabajo a término indefinido y 18 vinculados por contrato de trabajo a término fijo menor de un año" (p. 29).
A cierre de 2016, Comerciacoop resaltó como actividades de gestión social, entre otras, Mujeres Ahorradoras con Sueños "MAS", Programa de Educación Financiera "Yo y mis finanzas", Charlas de "Economía doméstica y educación financiera", Semilla Cooperativa, Apoyos Infantiles y Juveniles. De igual manera, la Asamblea General, mediante Acta 21 del 12 de marzo de 2016, autorizó a Comerciacoop el apoyo de tres proyectos radicados por la Confederación de Cooperativas de Colombia Boyacá, por un total de \$77 309315 (pp. $12,31-35$ ). A lo anterior se puede sumar un número considerable de alianzas con otros entes del orden cooperativo y algunos entes internacionales del sector.

Ahora bien, en 1996, la idea inicial de negocio consistía en generar beneficios económicos mediante la figura de captación y préstamo de dinero de unos cuantos socios provenientes de un gremio en particular. Veinte años después, el menú de servicios financieros y cooperativos que ofrece Comerciacoop tanto a sus miles de asociados como al público en general se compone de una amplia gama de productos que se pueden clasificar en tres líneas: de ahorro, de crédito y complementarios.

Los productos de ahorro, primera línea, comprenden programas como ahorros a la vista -Comerciahorrito, Ahorro Juvenil, Comerciadiario, Comerciacrédito, Ahorrocrédito, manejados mediante la tarjeta TAVA y el talonario de ahorros $-y$ ahorros contractuales o programados (Comerciafuturo, CDAT, Rentamás y CDAT navideño).

La segunda línea permite a sus asociados acceder a productos de crédito mediante tres modalidades: i) microcrédito -agropecuario, capital de trabajo, rotativo microcrédito, diferencial por plazo —créditos por días-, 
libre inversión, microcomercial —créditos grandes a microempresarios-, credinavidad, pagadiario, creditranquilidad - recoger cartera-; ii) de consumo -crediempleados, credigas -instalación servicio público de gas Valle de Tenza, crediahorro - crédito ahorrar enCDAT-, rotativo TAVA, diferencial por plazo, libre inversión, matrículas universitarias-; y iii) comercial -agropecuario, capital de trabajo, rotativo comercial, inversión, diferencial por plazo, liquidez, Navidad-.
Los servicios complementarios se prestan a través de alianzas estratégicas: seguros exequiales, en alianza con la Cooperativa de Servicios Funerarios Los Olivos; seguro de vida, en unión con La Equidad Seguros; $y$, adicional, servicios de giros nacionales a través del servicio de envíos y recepción de dinero de la red cooperativa giros nacionales Su Giro, pagos del programa Familias en Acción del Gobierno nacional y recaudo de servicios públicos Publiservicios, entre otros.

\section{Conclusiones}

ㄷn la administración de empresas como - práctica, se deben realizar constantes evaluaciones, entre otras razones, porque ello impulsa la innovación. Diferentes vías se pueden emplear para evaluar. Una de ellas consiste en sopesar el cumplimiento del plan estratégico. $Y$ para ello se puede comenzar con la misión y la visión institucionales. En ese entorno, vale preguntar si Comerciacoop ha cumplido con constituirse en una «cooperativa modelo de microfinanzas de los boyacenses» y si ha promovido «el desarrollo empresarial y la cultura solidaria, incrementando constantemente la base social y su capital de trabajo para garantizar a través de sus servicios, la satisfacción de las necesidades de sus asociados $y$, de esta manera, contribuir al bienestar económico y social, y al desarrollo regional». De acuerdo con lo reseñado a lo largo del artículo y los indicadores expuestos al final del anterior apartado, la respuesta es afirmativa.

Ahora, en consonancia con la historia empresarial, se considera pertinente visualizar la dinámica de las organizaciones y el papel que ha cumplido la administración en ese proceso. En otros términos, la historia empresarial empresarial de Comerciacoop ha de atender las epifanías y los acontecimientos que en sus veinte años configuraron un estado actual.

En primer lugar, los cuatro lustros de Comerciacoop pueden resumirse respecto de la perseverancia, la dedicación, la adaptabilidad y el servicio. El momento de la fundación de Comerciacoop -la epifanía de Jesús María Medina Duran de crear una empresa de servicios financieros dirigida a los comerciantes de Chiquinquirá- se dio en una época neurálgica en el sector financiero de Colombia. Etapa en la cual la crisis se apoderó en especial del sector cooperativo y la apertura de una cooperativa se veía absolutamente inviable, y menos si pertenecía a la rama de las finanzas. Sin embargo, la solidez de la idea propuesta por Jesús Medina tuvo acogida en la comunidad chiquinquireña, y a partir de la oportunidad que se dio gracias a la coyuntura del poder en la ciudad, el hecho fue bien aprovechado por Jesús Medina y secundado por el gremio de comerciantes de Chiquinquirá. 
Al comenzar, Comerciacoop tuvo grandes dificultades, las cuales se superaron gracias a la acción del gerente fundador y a las estrategias que se pusieron en marcha. Tales actos del orden administrativo configuraron los acontecimientos que han marcado el derrotero de la historia de Comerciacoop y que demuestran que ha existido una evolución en la organización gracias a un tránsito de un estado socioorganizacional a otro derivado de la administración como generadora de cambios, como creadora de historia.

Uno de tales actos, la realización de los dos coloquios de economía solidaria que contribuyeron a la autorización para ejercer la actividad financiera en calidad de excepción a montos mínimos que establecía la ley, posibilitó el paso de idea de negocio a la creación de un ente cooperativo ajustado a la normativa vigente. Esa gestión también permitió, más adelante, que organismos internacionales como el WOCCU prestaran asistencia técnica de forma indirecta a la cooperativa, hecho que redundó en el establecimiento formal de la estructura organizacional y el manejo de indicadores cooperativistas en entes de ahorro y crédito (PEARLS).

De igual modo, diversas estrategias han marcado giros en el continuum de la historia empresarial de Comerciacoop y pueden ser consideradas como acontecimientos: orientarse hacia el apoyo de los microempresarios mediante las microfinanzas con metodologías aportadas por WOCCU en 2005; comenzar, en 2009, con un proceso de expansión que redundaría en ofrecer una red de oficinas y corresponsales en el territorio boyacense y que, además, le permitió ser la primera cooperativa en el país con corresponsales no bancarios; y crear, en 2015, la unidad de microfinanzas con el fin de tener un área especializada. Las anteriores decisiones administrativas, consultadas por Jesús Medina al Consejo de Administración, han demarcado cambios de rumbo en pro del crecimiento y el desarrollo de Comerciacoop en cumplimiento de su objeto social y le han permitido, asimismo, ser conocida en la región y consolidarse como la cooperativa de los boyacenses.

En cuanto a los riesgos futuros a los que se enfrenta Comerciacoop, vale la pena anotar que ha configurado una cultura organizacional monolítica, centrada en la figura del gerente fundador Jesús María Medina Durán. Este hecho genera una preocupación en toda la organización debido a que Comerciacoop debe afrontar cambio de gerencia en un futuro no muy lejano; sin embargo, es preciso interrogarse si está, de hecho, preparada para que Jesús Medina abandone el cargo de gerente y lo ceda a un sucesor que conozca el sector cooperativo, a Comerciacoop, y que no permita que la filosofía de esta se pierda. Pero no solo el relevo generacional de la gerencia preocupa a Comerciacoop; algo similar ocurre en sus diferentes áreas, debido a la carencia de jóvenes líderes cooperativistas en la sociedad. 


\section{Referencias}

Arango, M. (2006). Evolución y crisis del sistema financiero colombiano. Bogotá: Naciones Unidas, Cepal.

Betancourt Zárate, G. (2003). De la historia empresarial a la historia organizacional. Innovar: Revista de CienciasAdministrativas y Sociales, 34(22), 199-210.

Chárriez Cordero, M. (2012). Historia de vida: una metodología de investigación cualitativa. Revista Griot, 5(1), 50-67.

Congreso de la República. Ley 454 de 1998. Por la cual se determina el marco conceptual que regula la economía solidaria...

Comerciacoop, Ahorro y crédito (2016). Informe de gestión 2016. Recuperado de http://www.comerciacoop.coop/site/ images/inf_gest_2016.pdf

Comerciacoop, ahorro y crédito (s. f.). Misión y visión. Recuperado de http:// www.comerciacoop.coop/site/index.php/ quienes-somos/mision-y-vision

Comerciacoop, Ahorro y crédito (s. f.). Objeto social. Recuperado de http:// www.comerciacoop.coop/site/index.php/ quienes-somos/objeto-social

Comerciaccop. (2016). Revista conmemorativa Comerciacoop en cifras. 20 años de Comerciacoop. 1996-2016.

Confecoop (2014). Desempeño sector cooperativo colombiano 2014. Recuperado de http://confecoop.coop/informesanuales/ informes-anuales/
Cooptenjo (s. f.). Orígenes del cooperativismo. Recuperado de http://www.cooptenjo. com/39027

Dávila Ladrón de Guevara Ladrón de Guevara, C. (2005). Historia empresarial y dirección estratégica: vecinos aislados con potencial de interacción. En G. Calderón Hernández G. y G. A. Castaño D. (comps.), Investigación en administración en América Latina: evolución y resultados (pp. 57-78). Manizales: Universidad Nacional de Colombia.

El Tiempo (23 marzo 1998). Temor por crisis cooperativa. Recuperado de http://www. eltiempo.com/archivo/documento/MAM791441

Fernández, J. (2010). Cuadernos tutoriales: Guía para la redacción de una monografía. San Juan: Universidad de Puerto Rico, Recinto de Piedras.

Mallimaci, F. y Giménez Bélivea, V. (2006). Historias de vida y método biográfico. En I. Vasilachis de Gialdino (coord.), Estrategias de investigación cualitativa (pp. 175-212). Barcelona: Gedisa.

Molina, C. (2016). Una visión de Comerciacoop desde la historia empresarial. Comerciacoop, 1996-2016, 20 años en Revista conmemorativa Comerciacoop en cifras. 20 años de Comerciacoop. 1996- 2016.

Ordoñez Santos, M. L. (2012). Dinámica del proceso de enseñanza en la asignatura de historia empresarial. FACE: Revista de la Facultad de Ciencias Económicas y Empresariales, 3(1), 23-32. 
Presidente de la República de Colombia. Decreto 1134 de 1989. Por el cual se reglamenta la actividad de ahorro y crédito desarrollada por las cooperativas y se dictan normas para el ejercicio de la actividad financiera por parte de estas .

Roberts, A. (2001). La teoría en la historia empresarial. Revista Empresa y Humanismo, 3(1), 147-174.

Romero Ibarra, M. E. (2003). La historia empresarial. Historia Mexicana, 52(3), 804-829.

Roncancio, C. (2016). La historia empresarial: elementos conceptuales, teoría, metodología e incidencias en la formación del administrador de empresas (Tesis de grado, Universidad Pedagógica y Tecnológica de Colombia, Chiquinquirá, Colombia).

Torres, A. (2002). Estrategias y técnicas de investigación cualitativa. Bogotá: UNAD.

Uribe Garzón, C. (1997). Orígenes del cooperativismo en Colombia. El Tiempo. Recuperado de http://www.eltiempo. com/archivo/documento/MAM-568354

Valderrama Días, R. (1999). Auge, crisis y recesión económica colombiana: años noventa. Apuntes del Cenes, 18(27-28), 237-246.

Zuluaga, J. C. (2010). Emprendimiento e Historia Empresarial. Apuntes para un diálogo interdisciplinario en América Latina. Ponencia presentada en el I Congreso Latinoamericano de Historia
Económica, Asociación Mexicana de Historia Económica, México.

\section{Entrevistas}

Asociados fundadores, entrevista por Ingrith Marcela Cano Cancelado y Melissa Pedroza Buitrago, 14 y 19 de julio de 2016.

Clara Franco, subgerente comercial y de mercadeo Comerciacoop, entrevista por Ingrith Marcela Cano Cancelado y Melissa Pedroza Buitrago, 29 de junio y 5 de julio de 2016.

Consejo de Administración de Comerciacoop, Chiquinquirá, entrevista por Ingrith Marcela Cano Cancelado y Melissa Pedroza Buitrago, 27 de junio de 2016.

Funcionarios de Comerciacoop, entrevista por Ingrith Marcela Cano Cancelado y Melissa Pedroza Buitrago, 6 de julio de 2016.

Jesús María Medina Durán, gerente Cooperativa de Comerciantes Comerciacoop, entrevista por Ingrith Marcela Cano Cancelado y Melissa Pedroza Buitrago, 27 de marzo, 13 y 14 de junio de 2016.

Milena García, subgerente de riesgos y oficial de cumplimiento Comerciacoop, entrevista por Ingrith Marcela Cano Cancelado y Melissa Pedroza Buitrago, 29 de junio y 5 de julio 2016. 